This is the author's final, peer-reviewed manuscript as accepted for publication. The publisher-formatted version may be available through the publisher's web site or your institution's library.

\title{
Towards understanding structural changes of photoperiod- sensitive sorghum biomass during sulfuric acid pretreatment
}

Feng $\mathrm{Xu}$, Yong-Cheng Shi, Donghai Wang

\section{How to cite this manuscript}

If you make reference to this version of the manuscript, use the following information:

Xu, F., Shi, Y.-C., \& Wang, D. (2013). Towards understanding structural changes of photoperiod-sensitive sorghum biomass during sulfuric acid pretreatment. Retrieved from http://krex.ksu.edu

\section{Published Version Information}

Citation: Xu, F., Shi, Y.-C., \& Wang, D. (2013). Towards understanding structural changes of photoperiod-sensitive sorghum biomass during sulfuric acid pretreatment. Bioresource Technology, 135, 704-709.

Copyright: Published by Elsevier Ltd.

Digital Object Identifier (DOI): doi:10.1016/j.biortech.2012.08.141

Publisher's Link: http://www.sciencedirect.com/science/article/pii/S0960852412013363

This item was retrieved from the K-State Research Exchange (K-REx), the institutional repository of Kansas State University. K-REx is available at http://krex.ksu.edu 


\title{
Towards understanding structural changes of photoperiod-sensitive sorghum biomass during sulfuric acid pretreatment
}

Feng Xua ${ }^{\text {a }}$, Yong-Cheng Shi ${ }^{\mathrm{b}, *}$, Donghai Wang ${ }^{\mathrm{a},{ }^{*}}$

${ }^{a}$ Department of Biological and Agricultural Engineering, Kansas State University, Manhattan, Kansas 66506; ${ }^{\mathrm{b}}$ Department of Grain Science and Industry, Kansas State University, Manhattan, Kansas 66506

\begin{abstract}
Wide-angle X-ray diffraction (WAXD) and small-angle X-ray scattering (SAXS) were employed to investigate the structural changes of photoperiod-sensitive sorghum biomass in both crystalline and amorphous domains after sulfuric acid pretreatment. WAXD results suggested that the crystalline cellulose melted at $120^{\circ} \mathrm{C}$ without significant polymer degradation and cellulose went through a simultaneous hydrolysis and crystallization at $160{ }^{\circ} \mathrm{C}$. Both the cellulose crystallinity and the crystal size increased as the temperature increased, which might lower cellulose digestibility. The efficiency of enzymatic hydrolysis (EEH) increased because the cellulose protective structure was compromised and most hemicellulose was removed, resulting in an increase in total surface area as suggested by SAXS results. The radius of gyration of the polymer structure decreased and the lamellar structure was destroyed after pretreatment. Both the EEH and cellulose degradation increased as the temperature increased. The total glucose yield increased to $79.7 \%$ as the temperature increased to $160{ }^{\circ} \mathrm{C}$.
\end{abstract}

Keywords: biomass structure; WAXD; SAXS; cellulose; acid pretreatment; enzymatic hydrolysis.

\section{Introduction}

Lignocellulosic biomass for biofuel production has attracted much attention because of its abundance and renewability. Photoperiod-sensitive (PS) sorghum, due to its advantages of drought tolerance, relatively low lignin content, and high soluble sugar content, is a promising biomass source for bioethanol production (Xu et al., 2011a). Pretreatment is a crucial step in

* Corresponding authors. Tel.: +1 785532 2919; fax: +1 7855325825 . E-mail address: ycshi@ksu.edu (Y. Shi), dwang@ksu.edu (D. Wang). 
biomass-ethanol conversion; its goals are to break the lignin/hemicellulose seal, disrupt the crystalline structure of cellulose, and increase the total surface area of cellulose to make the polysaccharides more susceptible to enzyme hydrolysis (Mosier et al., 2005; Whitfield et al., 2012). Numerous pretreatment methods have been employed for biomass processing, such as steam explosion, dilute acid, alkali, ammonia fiber explosion, and supercritical $\mathrm{CO}_{2}(\mathrm{Wu}$ et al., 2011). Among these methods, diluted sulfuric acid pretreatment has been used frequently in biomass-ethanol processing (Saha et al., 2005). An important advantage of acid pretreatment is that it is able to remove most hemicellulose from biomass and increase the total surface area of cellulose for enzymatic hydrolysis (Zeng et al., 2007). The removed hemicellulose could be degraded to monosaccharides, which could be used for ethanol production or be further degraded to furfural for chemical use. Another effect of acid hydrolysis on cellulose is the decrease of degree of polymerization, leading to the creation of reducing ends of cellulose (Knappert et al., 1980).

A review of the literature reveals that the structural changes of biomass during pretreatment are complex and not completely understood. There are arguments about the changes of crystalline structure of biomass during pretreatment. The question whether the crystallinity of biomass substrate affects enzymatic hydrolysis is in debate (Mansfield et al., 1999). Biomass crystallinity, which represents the mass percentage of crystalline component in whole mass rather than in cellulose, has been used frequently as a parameter of structural changes (Park et al., 2010). However, biomass crystallinity could be affected by the compositional changes of noncellulose amorphous components (e.g., hemicellulose) and even extractives, providing limited information about crystalline structure. Thus, cellulose crystallinity, a percentage of crystalline part in cellulose, is suggested and was used in this study. 
Both the compositional and structural changes of non-cellulose components (e.g., hemicellulose) by acid pretreatment could affect the digestibility of cellulose in biomass, but it is critical to understand the structural changes of cellulose after pretreatment. Wide-angle X-ray diffraction (WAXD) is effective for studying the crystalline structure of polymers (Park et al., 2010), and small-angle X-ray scattering (SAXS) is able to probe structure from approximately 1 $\mathrm{nm}$ to hundreds of nanometers (Chu and Hsiao, 2001). Recent studies using small-angle neutron scattering have revealed biomass structural changes during various pretreatments (Li et al., 2011; Pingali et al., 2010), but questions about the detailed changes of cellulose remained unanswered. Our previous study using both WAXD and SAXS has provided the structural information of different botanic parts of biomass and has shown that biomass goes through structure change in both crystalline and amorphous domains during acid and alkali pretreatments (Xu et al., 2012). Although the results are very promising, a study with multiple acid pretreatment conditions (e.g., severity) is suggested to provide detailed information on the structure changes of biomass, allowing us to understand the mechanism of pretreatment. In addition, further study is necessary to reveal the relationship between structural changes and hydrolysis efficiency.

To the best of our knowledge, the structural changes of biomass during acid pretreatment, especially the detailed changes of crystalline cellulose, have not been fully understood. In this study, both WAXD and SAXS with synchrotron radiation helped us understand the structural changes of biomass in a large length scale and their effects on enzymatic hydrolysis. Both the biomass rind and powder were used for the investigation of structural change. Biomass rind is the out layer of sheath and crystal structure of cellulose in rind has orientation (Xu et al., 2012). A study using biomass rind is helpful for understanding the nanostructure related to orientation; a study using biomass powder is more beneficial for understanding the direct effects of 
pretreatment on subsequent processing such as enzymatic hydrolysis. Furthermore, a better understanding of biomass structural change will enable development of a cost-efficient strategy for biomass processing.

\section{Materials and Methods}

\subsection{Materials}

The PS sorghum was harvested at physiological maturity from Riley County, Kansas, in 2008. Three rinds were prepared by knife-cutting PS sorghum and air-drying in an oven at $50{ }^{\circ} \mathrm{C}$ for $12 \mathrm{~h}$. Detail information about the biomass preparation could be found in our previous report (Xu et al., 2012). Powder samples ( $<1 \mathrm{~mm}$ particle size) were prepared using a cutting mill (SM 2000, Retsch Inc., Newtown, PA). The compositional analysis of biomass was conducted by following the procedures from National Renewable Energy Laboratory (Sluiter et al., 2004). Accellerase ${ }^{\circledR} 1500$, an enzyme complex including cellulase and $\beta$-glucosidase (Endoglucanase activity: 2200-2900 CMC U/g (one CMC U unit of activity liberates $1 \mu$ mol of reducing sugars (expressed as glucose equivalents) in 1 min under specific assay conditions of $50^{\circ} \mathrm{C}$ and $\mathrm{pH}$ 4.8)), and Accellerase ${ }^{\circledR} \mathrm{XY}$, a hemicellulose enzyme complex (activity: 20000-30000 ABXU/g), were generously provided by Genencor (Rochester, NY). All the enzyme activity data were from the data sheets coming with the enzymes. All chemicals used in this research were of analytical grade and purchased from Sigma-Aldrich, Inc. (St. Louis, MO, USA).

\subsection{Acid pretreatment}

Both the PS sorghum powder and the rind were used for acid pretreatment. For biomass powder pretreatment, a prewashed sample in which the water-soluble extractive had been washed out as described (Xu et al., 2011a) was used as an untreated sample. For biomass rind pretreatment, a piece of PS sorghum rind $(0.5 \times 2 \mathrm{~cm})$ was submerged in sulfuric acid solution. A 
reactor (Swagelok, Kansas City Valve \& Fitting Co., Shawnee Mission, KS) made from 316L stainless steel with a measured internal volume of $75 \mathrm{~mL}$ (outside diameter of $38.1 \mathrm{~mm}$, length of $125 \mathrm{~mm}$, and wall thickness of $2.4 \mathrm{~mm}$ ) was used for this study. A working volume of 50mL was used to allow space for expanding liquid water at a high temperature during pretreatment. The loading of the prewashed PS sorghum was $6.1 \%(\mathrm{w} / \mathrm{v}, 3.07 \mathrm{~g}$ dry mass in $50 \mathrm{ml} 1.27 \%$ sulfuric acid solution). A sandbath (Techne, Inc., Princeton, NJ) with a temperature controller was used. After the heating medium attained a certain temperature, the reactor was submerged in the medium for $40 \mathrm{~min}$. Then the reactor was immediately transferred and cooled by roomtemperature water to decrease the internal temperature to below $50^{\circ} \mathrm{C}$ in $2 \mathrm{~min}$. The slurry removed from the reactor was washed, and the solid fraction was separated by filtration. Part of the solid mass from filtration was used for enzymatic hydrolysis, part of the air-dried sample was used for WAXD and SAXS measurement, and the remaining part and the liquid were used for composition analysis. Two replicates were obtained. Cellulose recovery yield ( $\left.\mathrm{Y}_{\mathrm{REC}}\right)$ was defined as shown in Equation 1.

$$
Y_{R E C}=\frac{M_{\text {pret }} \times C_{p r e t}}{M_{O R} \times C_{O R}} \times 100 \%
$$

where $\mathrm{M}_{\text {pret }}$ is the dry mass weight after pretreatment, $\mathrm{M}_{\mathrm{OR}}$ is the original dry mass weight, $\mathrm{C}_{\text {pret }}$ is the cellulose percentage of the solid part after pretreatment, and $\mathrm{C}_{\mathrm{OR}}$ is the percentage of the cellulose in original dry mass.

\subsection{Enzymatic hydrolysis}

Enzymatic hydrolysis was conducted with the pretreated powder at $2 \%$ solids concentration (grams dry weight per $100 \mathrm{~mL}$ ) in $50 \mathrm{mM}$ sodium acetate buffer (pH 5.00) with the addition of $40 \mu \mathrm{g} / \mathrm{mL}$ of tetracycline and $30 \mu \mathrm{g} / \mathrm{mL}$ of cycloheximide. The enzymes, Accellerase $^{\circledR} 1500$ and Accellerase ${ }^{\circledR} \mathrm{XY}$, were used at the recommended dosages of $0.5 \mathrm{~mL}$ per 
gram cellulose and $0.1 \mathrm{~mL}$ per gram cellulose, respectively. Total monosaccharide was analyzed at the end of hydrolysis (72 h) on supernatants using high-performance liquid chromatography (HPLC) equipped with reflective index detector (RID 10A, Shimadzu, MD, USA) and a Rezex RPM-monosaccharide column (Phenomenex, CA, USA) operated at $80^{\circ} \mathrm{C}$. Two replicates were obtained. The efficiency of enzymatic hydrolysis (EEH) was defined as shown in the following calculation:

$E E H=\frac{G_{E H} \times 0.9}{M_{E H} \times C_{p r e t}} \times 100 \%$

where $\mathrm{M}_{\mathrm{EH}}$ is the weight of dry mass used in enzymatic hydrolysis, $\mathrm{G}_{\mathrm{EH}}$ is the glucose content after hydrolysis, $\mathrm{C}_{\text {pret }}(\%)$ is the cellulose content of the solid part after pretreatment, and 0.9 is the mass coefficient of glucose to cellulose $(g / g)$. Total glucose yield $\left(Y_{p}\right)$ was defined as the product of cellulose percentage in the solid part after pretreatment and EEH.

$$
Y_{P}=\frac{E E H \times Y_{R E C}}{100 \%}
$$

\subsection{Synchrotron WAXD and SAXS}

The WAXD and SAXS experiments were carried out at the Advanced Polymers Beamline (X27C), National Synchrotron Light Source, Brookhaven National Laboratory, in Upton, NY. Details of the experimental setup at the X27C beamline have been reported elsewhere (Chu and Hsiao, 2001). The wavelength used was $0.13714 \mathrm{~nm}$. The sample-to-detector distance was $117.6 \mathrm{~mm}$ for WAXD and $1782.9 \mathrm{~mm}$ for SAXS. A 2D MAR-CCD X-ray detector (MAR USA, Inc., Norwood, NJ) was used for data collection. For X-ray study of PS rind, the direction of the X-ray beam was perpendicular to chip direction.

Two-dimensional WAXD patterns were first corrected with air background, then performed with Fraser correction using Polar software (Precision Works, NY). For the analysis 
of anisotropic features (e.g., (020) reflection) in a 2D pattern, the integrating range was from $70^{\circ}$ to $110^{\circ}$ instead of the range used for isotropic pattern, $0^{\circ}$ to $360^{\circ}$. Relative mass crystallinity ( $\mathrm{RCr}$, the percentage of crystalline cellulose in biomass) was the ratio of the total crystal peak diffraction intensity to the total diffraction intensity. A peak-fitting process was conducted with Igor Pro 6.20 (WaveMetrics Inc. Lake Oswego, OR). Cellulose crystallinity (CCr, the percentage of crystalline part in cellulose) was calculated using the following equation:

$C C r=\frac{R C r}{C_{\text {cell }}} \times 100 \%$

where $\mathrm{C}_{\text {cell }}(\%)$ is the cellulose content of an examined sample.

Crystal size of the anisotropic part was estimated from (020) reflection (Equation 1).

Because the Bragg reflection may be broadened by both crystallites with finite size and possible imperfections in the crystal lattice, the equation here was used only as a lower-bound estimate of crystal size.

$L_{w(h k l)}=\frac{K \lambda}{F W H M_{2 \theta} \cos \theta}[5]$

where $\theta$ is the Bragg angle corresponding to the plane, $K$ is a constant 0.9 for cellulose (Alexander, 1954), $\lambda$ is wavelength, and $\mathrm{FWHM}_{2 \theta}$ is the full width at half maximum of the reflection in the radial direction.

Two-dimensional SAXS data were corrected with air background before further analysis. The equatorial streak in the $2 \mathrm{D}$ pattern was analyzed for parameters related to the needle shaped microvoids aligned along the fiber direction following the equations below (Ruland, 1969).

$$
\begin{aligned}
& s^{2} B_{o b s}^{2}=1 / L^{2}+s^{2} B_{\phi}^{2} \\
& s B_{o b s}=1 / L+s B_{\phi}
\end{aligned}
$$


where $\mathrm{B}_{\mathrm{obs}}$ is the integral breadth at a given value of $\mathrm{s}, \mathrm{s}=2(\sin \theta) / \lambda, L$ is a uniform finite length of microvoids, and $\mathrm{B}_{\varphi}$ is the spread of the misorientation. Equations [6] and [7] are used if the azimuthal peak profiles are assumed to be Gaussian and Lorentzian, respectively. In this case, the Lorentzian function fit the peaks better and was employed.

The integrated 1D data were analyzed using Igor Pro 6.20 with the Irena package. The unified equation was used for analysis of SAXS data (Beaucage, 1995). The equation defines multiple levels, and each level may contain a Guinier region describing average structural size and a power-law region describing the mass or surface fractal. The unified model is given by: $I(q)=G_{i} \exp \left(-q^{2} R_{g i}^{2} / 3\right)+B_{i} \exp \left(-q^{2} R_{g(i-1)}^{2} / 3\right) \times\left\{\left[\operatorname{erf}\left(q R_{g i} / 6^{1 / 2}\right)\right]^{\beta} / q\right\}^{P i}$

where $i$ represents the structural levels, $\mathrm{G}_{\mathrm{i}}$ is the exponential prefactor, $\mathrm{R}_{\mathrm{gi}}$ is the radius of gyration, $\mathrm{B}_{\mathrm{i}}$ is a constant prefactor specific to the type of power-law scattering, $\mathrm{P}_{\mathrm{i}}$, and the magnitude of the scattering vector is defined as $\mathrm{q}=4 \pi \sin \theta / \lambda$ ( $\theta$ is half of the scattering angle).

\section{Results and discussion}

\subsection{Compositional changes of the PS sorghum after acid pretreatment}

Our previous study showed that pretreatment temperature was one of the most significant factors affecting biomass digestibility (Xu et al., 2011b). Thus, this study was designed to understand how the biomass structure changes at different temperatures. The compositional changes of the biomass after pretreatment were listed in Table 1. Biomass structure was disrupted during sulfuric acid pretreatment as previous reported (Xu et al., 2011a), resulting in significant compositional change. Xylan content was dramatically reduced because sulfuric acid effectively hydrolyzed hemicellulose. The increases in the percentages of glucan and lignin contents were results of mass loss (e.g., xylan removal) after the acid pretreatment.

\subsection{Structural changes of the PS sorghum}




\subsubsection{WAXD study}

After the sulfuric acid pretreatment, the crystalline structure of remaining biomass changed. Our previous study on PS sorghum rind suggested that a decrease in orientation factor was because the oriented crystalline structure was distorted by acid (Xu et al., 2012). In this study, the anisotropic flection was further investigated (Table 2). The crystallinity of the anisotropic fraction increased with the increasing pretreatment temperature as a result of the removal of the amorphous components after the pretreatment and washing. The change in crystal size estimated from the anisotropic fraction showed the similar trend of increase. The acid pretreatment at a relatively low temperature $\left(120^{\circ} \mathrm{C}\right)$ did not change the crystal size. A similar result was reported in our previous study at the same temperature (Xu et al., 2012). Further increasing the temperature resulted in an increase in crystal size. Crystallization of amorphous cellulose could be one reason for the increase in crystal size as found in the production of microcrystalline cellulose (Tang et al., 1996). A recent report also suggested the existence of templates of crystalline components at the dimension lateral to fiber direction (Ibbett et al., 2008); therefore, crystallization could begin at this dimension, resulting in the increase of crystal size in reflection (020). The increase in crystal size could lead to a decrease in the total surface area of cellulose, which might reduce chemical absorptions of cellulose fiber (Reddy and Yang, 2005) and might not be helpful for increasing the reaction rate of enzymatic hydrolysis.

In addition to the study of fiber diffraction, WAXD was used to investigate biomass powder. For better understanding the crystalline structure of biomass, we defined two terms of crystallinity: $\mathrm{RCr}$ (percentage of crystalline cellulose in biomass) and $\mathrm{CCr}$ (percentage of crystalline part in cellulose) as mentioned in section 2.4. Relative mass crystallinity, which was calculated with a peak-fitting procedure (Table 3), provides limited information about crystalline 
cellulose because biomass also contains other amorphous components besides cellulose.

Compared with the untreated sample, the $\mathrm{CCr}$ of pretreated samples decreased, suggesting that part of the crystalline cellulose was destroyed. Previous studies of acid treatment on cellulose reported that amorphous cellulose was preferentially hydrolyzed by acid (Bondeson et al., 2006). In this study, at $120^{\circ} \mathrm{C}$, acid preferentially hydrolyzes hemicellulose rather than amorphous cellulose (Table 1), possibly because the network structure of hemicellulose and lignin may protect amorphous cellulose from degradation (over 99\% recovery of cellulose) under this condition. In addition, the removal of hemicellulose by acid may help allow part of the crystalline cellulose to be melted at $120^{\circ} \mathrm{C}$, which could be related to a decrease in orientation factor as reported (Xu et al., 2012). The CCr increased as the temperature increased from 120 to $160^{\circ} \mathrm{C}$. This result has two possible explanations: acid preferentially hydrolyzed amorphous cellulose after removing most hemicellulose and eventually degraded much more amorphous cellulose than crystalline cellulose, and/or amorphous cellulose was crystallized simultaneously during acid hydrolysis (Bertran and Dale, 1985).

Cellulose recovery decreased as the temperature increased, indicating that cellulose degradation was enhanced as the severity of treatment conditions (e.g., temperature) increased. This was supported by our previous study using different acid concentration (Xu et al., 2011a). The recovery of crystalline cellulose was calculated to illuminate the effects of the acid treatment on the crystalline component in the insoluble fraction (Table 3). With pretreatment temperature increased from $120^{\circ} \mathrm{C}$ to $140^{\circ} \mathrm{C}$, the recovery of crystalline cellulose did not change significantly, but the recovery increased to $74.6 \%$ when the temperature was $160^{\circ} \mathrm{C}$. Since the cellulose recovery decreased from $96.8 \%$ to $87.4 \%$, we confirmed the simultaneous hydrolysis and crystallization during acid pretreatment at $160^{\circ} \mathrm{C}$. 


\subsubsection{SAXS study}

The effect of acid treatment on fiber structure was also investigated by SAXS. Two dimensional anisotropic patterns of PS sorghum rind (Fig. 1) suggested a high degree of orientation of the cellulose fibrils (Jungnikl et al., 2008). The untreated rind has both equatorial and meridional streaks (Fig. 1a), representing needle-shaped microvoids and periodic lamellar structure between the crystalline and amorphous regions, respectively (Chen et al., 2007). As the pretreatment temperature increased, the meridional streaks decreased, as found in the previous study (Xu et al., 2012). After the temperature was increased to $140{ }^{\circ} \mathrm{C}$, the meridional streak eventually disappeared, indicating that the lamellar structure was destroyed (Chen et al., 2007). The lengths and diameters of the needle-shaped microvoids could be estimated using Ruland's method (Ruland, 1969). The length of microvoids could be changed during various processing methods, and a recent report showed that the length of microvoids in regenerated cellulose fibers ranges from 333 to $1320 \mathrm{~nm}$ (Jiang et al., 2011). In this study, the estimated lengths of the microvoids increased as the temperature increased (Table 4), possibly because of the acid disruption of fiber structure. The length of the equatorial streak, which was considered a reciprocal of the diameter (D) of the microvoids in cellulose fibers (Ran et al., 2001), did not change significantly after acid treatment, indicating that the average diameter did not change. Considering that the length increased, we suggest that the total volume of the microvoids increased. In addition, the misorientation $\left(\mathrm{B}_{\varphi}\right)$ did not change at the relatively low temperatures but increased at a high temperature $\left(160^{\circ} \mathrm{C}\right)($ Table 4$)$, suggesting that the ordered structure could be disrupted under escalated pretreatment condition (Ran et al., 2001). Notable is that previous SAXS study on fiber suggested that microvoids changed significantly during drying and rewetting (Vickers et al., 2001). Also, the removal of the amorphous part could result in structure 
collapse with drying (Teleman et al., 2001). Thus, it would be interesting to study in situ structural change of biomass during processing.

A unified model was then employed to investigate the 1D SAXS curves from biomass powder (Fig. 2), and the related structural parameters were obtained (Table 4). In our previous study of PS sorghum rind, the $\mathrm{R}_{\mathrm{g}}$ decreased after acid treatment (Xu et al., 2012). A similar trend was found in this study using powder at a length scale of 600 to $1000 \AA$ (Table 4). At $120^{\circ} \mathrm{C}$, the $\mathrm{R}_{\mathrm{g}}$ did not change significantly, suggesting that the size of cellulose aggregates did not change. The results of cellulose composition and WAXD also suggested that part of cellulose melted but not degraded. The $\mathrm{R}_{\mathrm{g}}$ decreased as the temperature further increased to over $140{ }^{\circ} \mathrm{C}$, reflecting that part of cellulose was hydrolyzed by acid.

\subsection{Effects of the acid pretreatment on enzymatic hydrolysis}

The EEH and glucose yield of the pretreated PS sorghum powder increased significantly compared with that of untreated biomass (Fig. 3). As suggested by the composition analysis, the increase of the EEH was due to the sealed structure of amorphous components, such as hemicellulose, was disrupted and the cellulose in PS sorghum was exposed for the enzyme reaction. The increased volume of microvoids noted by SAXS contributed to an increased total surface area for the enzyme reaction. Another reason was that the decreased $\mathrm{CCr}$ after the pretreatment is helpful for increasing the reaction rate of enzymatic hydrolysis (Fan et al., 1980). As the pretreatment temperature increased, both the $\mathrm{EEH}$ and the $\mathrm{CCr}$ increased, whereas the cellulose recovery decreased. Previous study (Fan et al., 1980) on highly pure cellulose (99.5\%) showed that hydrolysis yield increased as the crystallinity of cellulose substrate decreased. In this study, the acid pretreatment not only changed cellulose structure but also affected other components in the PS sorghum. Cellulose is embeded in the matrix of hemicellulose and lignin. 
The removal of hemicellulose with enhanced conditions (e.g., higher temperature) of pretreatment exposed cellulose to enzymatic hydrolysis, although crystalline structure of cellulose remained to be resistant to enzymatic hydrolysis. At $160{ }^{\circ} \mathrm{C}$, The total glucose yield increased and was maximized at $79.7 \%$ with an EEH of $91.2 \%$ and a cellulose recovery of $87.4 \%$. As found in our previous study, the EEH could be enhanced up to $100 \%$ at a higher temperature (e.g., $180^{\circ} \mathrm{C}$ ), but the significant cellulose degradation made the total glucose yield less than $60 \%$ (Xu et al., 2011b). Therefore, a pretreatment for maximizing glucose yield needs to balance between EEH and cellulose recovery.

\subsection{Understanding the effects of sulfuric acid pretreatment on biomass}

For the whole biomass, the acid pretreatment disrupted the network structure among carbohydrate polymers and broke the hydrogen bonds between hemicellulose and cellulose, which eventually increased the enzymatic-accessible area of cellulose (Mosier et al., 2005). The SAXS results suggested an increased volume of microvoids after the acid pretreatment, which could be related to the conclusion in a previous study that the presence of hollow area after acid pretreatment is due to "peeling-away" of the components in plant cell wall (Zeng et al., 2007). The microvoids in biomass structure represent the needle-shaped space adjacent to cellulose. The increase in the microvoids length/volume contributed to the increase in total surface area. Previous study suggested that the size of cellulase is around 3-4 nm in diameter (Stone et al., 1969), which is smaller than the average diameter of microvoids (around 6-7 nm) measured in this report. Thus, an increase in microvoids length/volume could contribute to the increase of total surface area of cellulose, explaining the enhanced yield of enzymatic hydrolysis. The acid pretreatment at $120^{\circ} \mathrm{C}$ partially removed hemicellulose and caused melting of part of crystalline cellulose rather than significantly changed cellulose content, possibly because the remaining 
lignin and hemicellulose, at the relatively mild condition, maintained a protective structure, preventing the acid hydrolysis of cellulose (Chen and Dixon, 2007). The acid reaction at an escalated condition (e.g., the higher temperature) dramatically disrupted the biomass structure by removing most of hemicellulose and hydrolyzed the glucosidic linkages of glucan chains, eventually resulting in the significant hydrolysis of cellulose.

For the component of cellulose, the WAXD results suggested the melting of part of crystalline cellulose at $120^{\circ} \mathrm{C}$, possibly because acid broke up the interchain hydrogen-bonds and damaged part of the ordered crystalline structure of the cellulose. The fact that over $99 \%$ of cellulose was recovered at $120^{\circ} \mathrm{C}$ is consistent with the result that the $\mathrm{R}_{\mathrm{g}}$ did not change significantly (Table 4). When the temperature was over $140{ }^{\circ} \mathrm{C}$, the lamellar structure was destroyed, and the amount of both crystalline and amorphous cellulose decreased, as confirmed by the decreased $\mathrm{R}_{\mathrm{g}}$. The acid pretreatment at $160{ }^{\circ} \mathrm{C}$ eventually resulted in significant cellulose loss and an increased misorientation factor, indicating the disruption of biomass by acid. Crystallization of amorphous cellulose was confirmed by the increased recovery of crystalline cellulose and the increased crystal size in the dimension lateral to fiber direction. Simultaneous degradation and crystallization of amorphous cellulose was suggested. The significant decrease of $\mathrm{CCr}$ after the acid pretreatment made cellulose more susceptible to enzyme reaction (Chang and Holtzapple, 2000; Fan et al., 1980). However, the increase in the crystal size may not be helpful for enzyme reaction.

Lignin serves as a protective seal for cellulose (Mosier et al., 2005) and was considered as a cellulase inhibitor because of its irreversible absorption onto the enzyme (Berlin et al., 2005). The PS sorghum used in this study contained a relatively low lignin content compared with corn stover (17-21\%), which is an advantage for enzymatic hydrolysis. After the acid pretreatment, 
most lignin was preserved because sulfuric acid pretreatment is not effective for removing lignin. A previous study suggested that the structure of lignin could be rearranged during acid treatment, and the deposition of formed droplet would have a negative effect on enzymatic hydrolysis (Selig et al., 2007). In this study, the hydrolysis yield after pretreatment increased significantly. Because lignin composition and structure varies in different biomass, further research is needed to study the effect of the structural change of lignin on biomass processing.

\section{Conclusions}

Acid pretreatment changed the composition and structure of the PS sorghum and made cellulose more exposed and susceptible for enzymatic hydrolysis. Acid preferentially hydrolyzed hemicellulose rather than amorphous cellulose at $120^{\circ} \mathrm{C}$. Both the $\mathrm{CCr}$ and the crystal size of cellulose increased as the temperature increased, indicating that a higher temperature could make cellulose less susceptible. A simultaneous hydrolysis and crystallization was suggested at $160{ }^{\circ} \mathrm{C}$. The increased total volume of the microvoids contributed to an increased total surface area. The radius of gyration of the polymer structure decreased and the lamellar structure was destroyed after the acid pretreatment.

\section{Acknowledgement}

We thank Drs. Jun Wang, Benjamin S. Hsiao, and Lixia Rong for their assistance in WAXD and SAXS studies. Use of the National Synchrotron Light Source, Brookhaven National Laboratory, was supported by the U.S. Department of Energy, Office of Science, Office of Basic Energy Sciences, under Contract No. DE-AC02-98CH10886. The study was supported in part by the Center for Sustainable Energy, Kansas State University. This is contribution no. 12-335-J from the Kansas Agricultural Experiment Station. 


\section{References}

1. Alexander, L. 1954. The synthesis of X-ray Spectrometer line profiles with application to crystallite size measurements. J. Appl. Phys. 25, 155.

2. Beaucage, G. 1995. Approximations leading to a unified exponential/power-law approach to small-angle scattering. J. Appl. Crystallogr. 28, 717-728.

3. Berlin, A., Gilkes, N., Kurabi, A., Bura, R., Tu, M., Kilburn, D., Saddler, J. 2005. Weak lignin-binding enzymes. Appl. Biochem. Biotechnol. 121, 163-170.

4. Bertran, M., Dale, B. 1985. Enzymatic hydrolysis and recrystallization behavior of initially amorphous cellulose. Biotechnol. Bioeng. 27, 177-181.

5. Bondeson, D., Mathew, A., Oksman, K. 2006. Optimization of the isolation of nanocrystals from microcrystalline cellulose by acid hydrolysis. Cellulose 13, 171-180.

6. Chang, V., Holtzapple, M. 2000. Fundamental factors affecting biomass enzymatic reactivity. Appl. Biochem. Biotechnol. 84, 5-37.

7. Chen, F., Dixon, R.A. 2007. Lignin modification improves fermentable sugar yields for biofuel production. Nat. Biotechnol. 25, 759-761.

8. Chen, X., Burger, C., Wan, F., Zhang, J., Rong, L., Hsiao, B., Chu, B., Cai, J., Zhang, L. 2007. Structure study of cellulose fibers wet-spun from environmentally friendly $\mathrm{NaOH} /$ urea aqueous solutions. Biomacromolecules 8, 1918-1926.

9. Chu, B., Hsiao, B. 2001. Small-angle x-ray scattering of polymers. Chem. Rev. 101, 1727-1762.

10. Fan, L., Lee, Y., Beardmore, D. 1980. Mechanism of the enzymatic hydrolysis of cellulose: effects of major structural features of cellulose on enzymatic hydrolysis. Biotechnol. Bioeng. 22, 177-199.

11. Ibbett, R., Domvoglou, D., Phillips, D.A.S. 2008. The hydrolysis and recrystallisation of lyocell and comparative cellulosic fibres in solutions of mineral acid. Cellulose 15, 241254.

12. Jiang, G., Huang, W., Li, L., Wang, X., Pang, F., Zhang, Y., Wang, H. 2011. Structure and properties of regenerated cellulose fibers from different technology processes. Carbohydr. Polym. doi:10.1016/j.carbpol.2011.10.022.

13. Jungnikl, K., Paris, O., Fratzl, P., Burgert, I. 2008. The implication of chemical extraction treatments on the cell wall nanostructure of softwood. Cellulose 15, 407-418.

14. Knappert, D., Grethlein, H., Converse, A. 1980. Partial acid hydrolysis of cellulosic materials as a pretreatment for enzymatic hydrolysis. Biotechnol. Bioeng. 22, 1449-1463.

15. Li, C., Cheng, G., Balan, V., Kent, M.S., Ong, M., Chundawat, S.P.S., daCosta Sousa, L., Melnichenko, Y.B., Dale, B.E., Simmons, B.A. 2011. Influence of Physico-Chemical Changes on Enzymatic Digestibility of Ionic Liquid and AFEX pretreated Corn Stover. Bioresour. Technol. 102, 6928-6936.

16. Mansfield, S.D., Mooney, C., Saddler, J.N. 1999. Substrate and enzyme characteristics that limit cellulose hydrolysis. Biotechnol. Progr. 15, 804-816.

17. Mosier, N., Wyman, C., Dale, B., Elander, R., Lee, Y., Holtzapple, M., Ladisch, M. 2005. Features of promising technologies for pretreatment of lignocellulosic biomass. Bioresour. Technol. 96, 673-686.

18. Park, S., Baker, J., Himmel, M., Parilla, P., Johnson, D. 2010. Cellulose crystallinity index: measurement techniques and their impact on interpreting cellulase performance. Biotechnology for Biofuels 3, 10. 
19. Pingali, S.V., Urban, V.S., Heller, W.T., McGaughey, J., O’Neill, H., Foston, M., Myles, D.A., Ragauskas, A., Evans, B.R. 2010. Breakdown of cell wall nanostructure in dilute acid pretreated biomass. Biomacromolecules 11, 2329-2335.

20. Ran, S., Fang, D., Zong, X., Hsiao, B., Chu, B., Cunniff, P. 2001. Structural changes during deformation of Kevlar fibers via on-line synchrotron SAXS/WAXD techniques. Polymer 42, 1601-1612.

21. Reddy, N., Yang, Y. 2005. Structure and properties of high quality natural cellulose fibers from cornstalks. Polymer 46, 5494-5500.

22. Ruland, W. 1969. Small-angle scattering studies on carbonized cellulose fibers. Journal of Polymer Science Part C: Polymer Symposia 28, 143-151.

23. Saha, B.C., Iten, L.B., Cotta, M.A., Wu, Y.V. 2005. Dilute acid pretreatment, enzymatic saccharification and fermentation of wheat straw to ethanol. Process Biochem. 40, 36933700.

24. Selig, M.J., Viamajala, S., Decker, S.R., Tucker, M.P., Himmel, M.E., Vinzant, T.B. 2007. Deposition of lignin droplets produced during dilute acid pretreatment of maize stems retards enzymatic hydrolysis of cellulose. Biotechnol. Progr. 23, 1333-1339.

25. Sluiter, A., Hames, B., Ruiz, R., Scarlata, C., Sluiter, J., Templeton, D., Crocker, D. 2004. Determination of structural carbohydrates and lignin in biomass. NREL, Golden, CO.

26. Stone, J., Scallan, A., Donefer, E., Ahlgren, E. 1969. Digestibility as a simple function of a molecule of similar size to a cellulase enzyme. Adv. Chem. Ser 95, 219-241.

27. Tang, L.G., Hon, D.N.S., Pan, S.H., Zhu, Y.Q., Wang, Z., Wang, Z.Z. 1996. Evaluation of microcrystalline cellulose. I. Changes in ultrastructural characteristics during preliminary acid hydrolysis. J. Appl. Polym. Sci. 59, 483-488.

28. Teleman, A., Larsson, P., Iversen, T. 2001. On the accessibility and structure of xylan in birch kraft pulp. Cellulose 8, 209-215.

29. Vickers, M., Briggs, N., Ibbett, R., Payne, J., Smith, S. 2001. Small angle X-ray scattering studies on lyocell cellulosic fibres: the effects of drying, re-wetting and changing coagulation temperature. Polymer 42, 8241-8248.

30. Whitfield, M.B., Chinn, M.S., Veal, M.W. 2012. Processing of materials derived from sweet sorghum for biobased products. Ind. Crop Prod. 37, 362-375.

31. Wu, L., Arakane, M., Ike, M., Wada, M., Takai, T., Gau, M., Tokuyasu, K. 2011. Low temperature alkali pretreatment for improving enzymatic digestibility of sweet sorghum bagasse for ethanol production. Bioresour. Technol. 102, 4793-4799.

32. Xu, F., Shi, Y.-C., Wang, D. 2012. Structural features and changes of lignocellulosic biomass during thermochemical pretreatments: A synchrotron X-ray scattering study on photoperiod-sensitive sorghum. Carbohydr. Polym. 88, 1149-1156.

33. Xu, F., Shi, Y.-C., Wu, X., Theerarattananoon, K., Staggenborg, S., Wang, D. 2011 a. Sulfuric acid pretreatment and enzymatic hydrolysis of photoperiod sensitive sorghum for ethanol production. Bioprocess and Biosystems Engineering 34, 485-492.

34. Xu, F., Theerarattananoon, K., Wu, X., Pena, L., Shi, Y.C., Staggenborg, S., Wang, D. 2011 b. Process optimization for ethanol production from photoperiod-sensitive sorghum: Focus on cellulose conversion. Ind. Crop Prod. 34, 1212-1218.

35. Zeng, M., Mosier, N., Huang, C., Sherman, D., Ladisch, M. 2007. Microscopic examination of changes of plant cell structure in corn stover due to hot water pretreatment and enzymatic hydrolysis. Biotechnol. Bioeng. 97, 265-278. 


\section{Figure captions}

Figure 1. Small-angle X-ray scattering of the photoperiod-sensitive sorghum rinds (A: untreated; B: acid treated at $120^{\circ} \mathrm{C}$; C: acid treated at $140{ }^{\circ} \mathrm{C}$; D: acid treated at $160{ }^{\circ} \mathrm{C}$ ) and a schematic diagram of microvoids. ( $\mathrm{D}$ represents the average diameter of the needle-shaped microvoids.)

Figure 2. The unified fit of small-angle X-ray scattering profile of photoperiod-sensitive sorghum with acid pretreatments. The curves were shifted vertically for better visualization.

Figure 3. The effects of the pretreatment on efficiency of enzymatic hydrolysis (EEH), cellulose recovery (Rec), and glucose yield (Glu. Yield). 

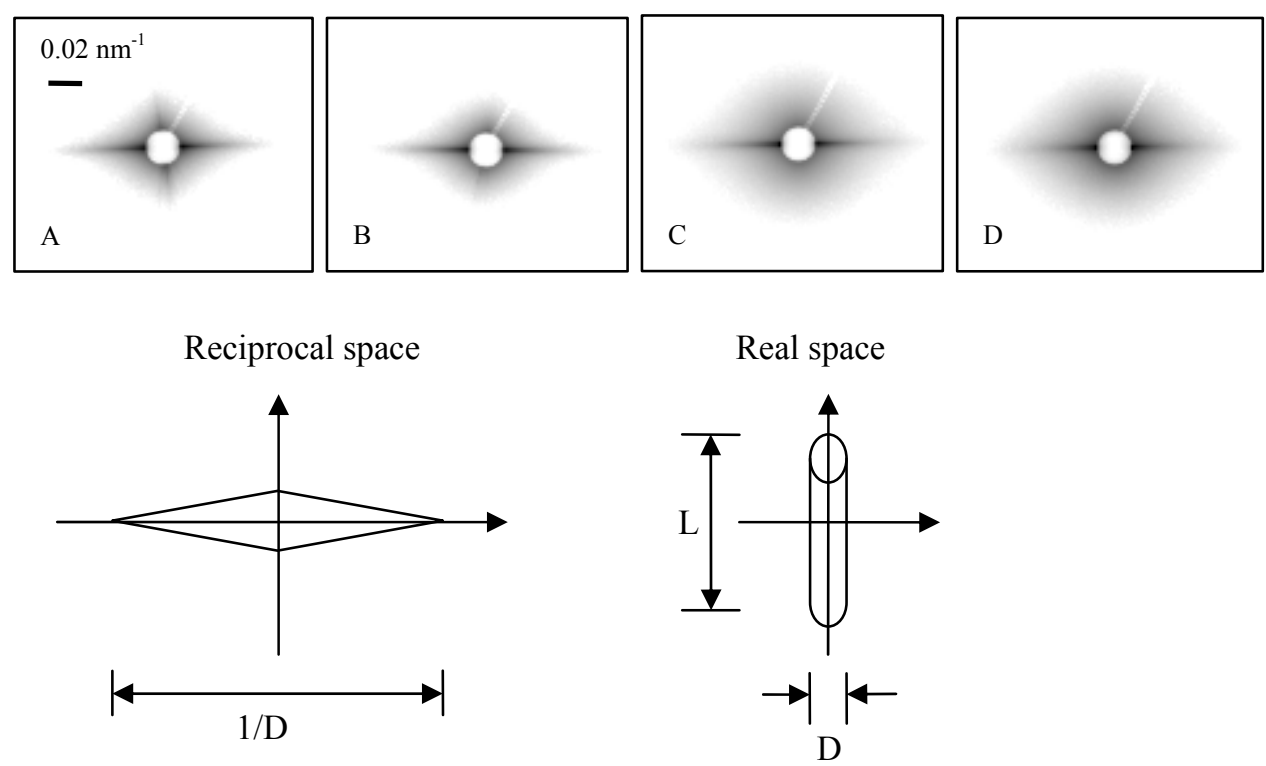

Figure 1. Small-angle X-ray scattering of the photoperiod-sensitive sorghum rinds (A: untreated; B: acid treated at $120^{\circ} \mathrm{C}$; C: acid treated at $140{ }^{\circ} \mathrm{C}$; D: acid treated at $160{ }^{\circ} \mathrm{C}$ ) and a schematic diagram of microvoids. (D represents the average diameter of the needle-shaped microvoids.) 




Figure 2. The unified fit of small-angle X-ray scattering profile of photoperiod-sensitive sorghum with acid pretreatments. The curves were shifted vertically for better visualization. 


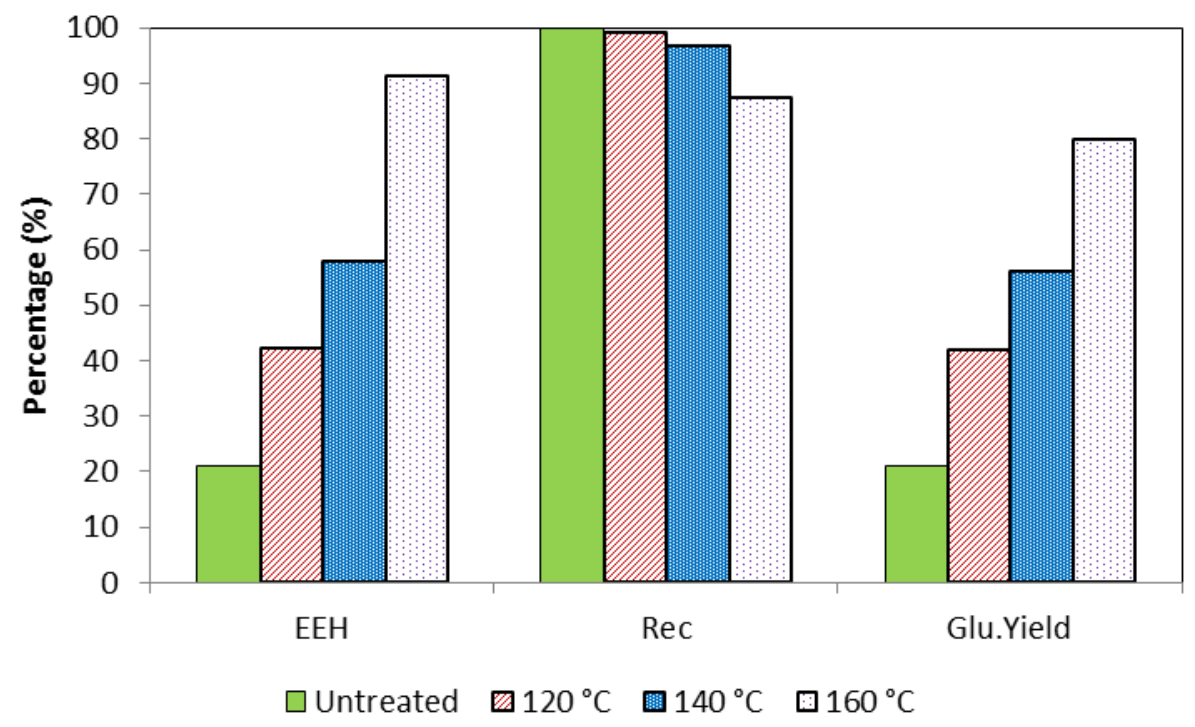

Figure 3. The effects of the pretreatment on efficiency of enzymatic hydrolysis (EEH), cellulose recovery (Rec), and glucose yield (Glu. Yield). 
Table 1. Compositional changes of PS sorghum with sulfuric acid pretreatment. ${ }^{\text {a }}$

\begin{tabular}{lccc}
\hline Conditions & Lignin & Xylan & Glucan \\
\hline untreated & $16.6(0.9)$ & $27.0(0.3)$ & $44.3(0.8)$ \\
$120^{\circ} \mathrm{C}$ & $21.9(1.5)$ & $14.7(0.4)$ & $57.3(0.4)$ \\
$140{ }^{\circ} \mathrm{C}$ & $24.8(1.8)$ & $5.5(0.1)$ & $64.9(0.9)$ \\
$160^{\circ} \mathrm{C}$ & $27.4(1.6)$ & $2.2(0.1)$ & $64.2(0.7)$ \\
\hline
\end{tabular}

${ }^{\mathrm{a}}$ Values (\%, dry based) in parenthesis represent standard deviation. 
Table 2. Crystallinity and crystal size of anisotropic part in PS sorghum rind analyzed using WAXD. ${ }^{\mathrm{a}}$

\begin{tabular}{lcc}
\hline Conditions & $\begin{array}{c}\text { Mass crystallinity of anisotropic } \\
\text { part (\%) }\end{array}$ & $\begin{array}{c}\text { Crystal size of anisotropic part (020) } \\
\text { reflection (nm) }\end{array}$ \\
\hline Untreated & $40.7(0.4)$ & $3.37(0.09)$ \\
$120{ }^{\circ} \mathrm{C}$ & $46.4(0.6)$ & $3.37(0.12)$ \\
$140{ }^{\circ} \mathrm{C}$ & $49.3(0.7)$ & $3.62(0.02)$ \\
$160{ }^{\circ} \mathrm{C}$ & $53.5(0.6)$ & $3.93(0.14)$ \\
\hline
\end{tabular}

${ }^{\mathrm{a}}$ Values in parenthesis represent standard deviation. Mass crystallinity represents the percentage of crystalline cellulose in biomass. 
Table 3. Changes of cellulose content (\%) and crystallinity (\%) of PS sorghum analyzed using WAXD. ${ }^{\mathrm{a}}$

\begin{tabular}{ccccc}
\hline Conditions & $\begin{array}{c}\text { Cellulose } \\
\text { recovery }\end{array}$ & $\begin{array}{c}\text { Mass } \\
\text { crystallinity }\end{array}$ & $\begin{array}{c}\text { Cellulose } \\
\text { crystallinity }\end{array}$ & $\begin{array}{c}\text { Recovery of crystalline } \\
\text { cellulose }\end{array}$ \\
\hline Untreated & 100.0 & $32.4(0.9)$ & 78.5 & 100.0 \\
$120^{\circ} \mathrm{C}$ & $99.1(0.1)$ & $28.6(0.5)$ & 51.2 & 64.6 \\
$140^{\circ} \mathrm{C}$ & $96.8(0.3)$ & $33.3(0.9)$ & 53.6 & 66.1 \\
$160^{\circ} \mathrm{C}$ & $87.4(0.3)$ & $41.3(0.8)$ & 67.0 & 74.6 \\
\hline
\end{tabular}

${ }^{\mathrm{a}}$ Values in parenthesis represent standard deviation. Mass crystallinity represents the percentage of crystalline cellulose in biomass. Cellulose crystallinity represents the percentage of crystalline part in cellulose. Recovery of crystalline cellulose was calculated based on the cellulose content of untreated biomass (100\%).

${ }^{\mathrm{b}}$ Calculated from air-dried washed PS sorghum powder. 
Table 4. SAXS parameters of structural changes of biomass. ${ }^{\text {a }}$

\begin{tabular}{lccc}
\hline Conditions & $\mathrm{R}_{\mathrm{g}}(\AA)$ & $\mathrm{L}(\mathrm{nm})$ & $\mathrm{B}_{\varphi}(\mathrm{rad})$ \\
\hline Prewashed powder & 350 & 790 & 0.15 \\
$120^{\circ} \mathrm{C}$ acid & 351 & 974 & 0.14 \\
$140^{\circ} \mathrm{C}$ acid & 330 & 1166 & 0.14 \\
$160^{\circ} \mathrm{C}$ acid & 277 & 1319 & 0.21 \\
\hline
\end{tabular}

${ }^{a} R_{g}$ is radius of gyration, $L$ is a uniform finite length of microvoids, and $B_{\varphi}$ is the spread of the misorientation. 